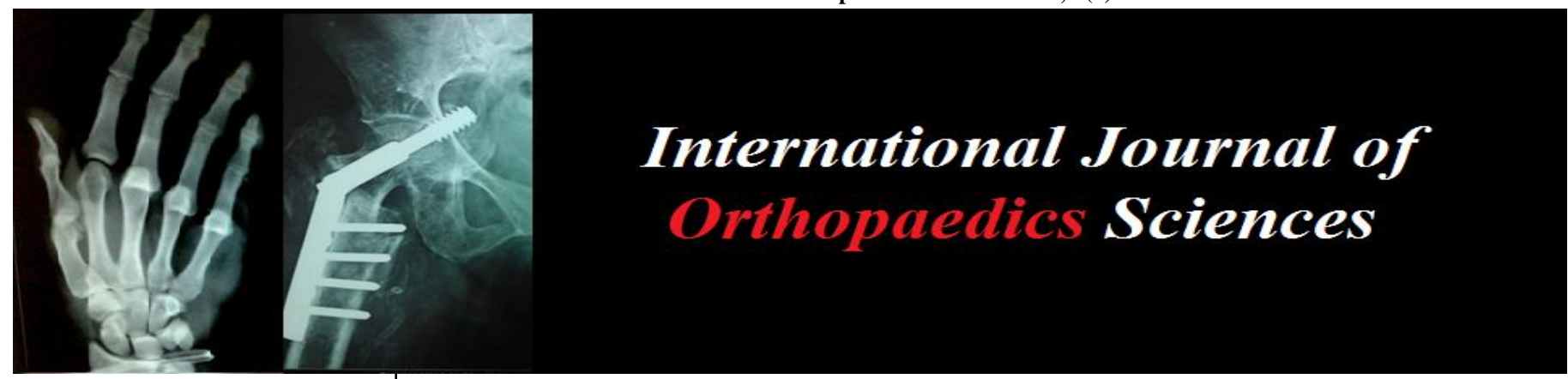

E-ISSN: 2395-1958

P-ISSN: 2706-6630

IJOS 2019; 5(4): 137-143

(C) 2019 IJOS

www.orthopaper.com

Received: 16-08-2019

Accepted: 20-09-2019

Kanagasarathy K

Department of Orthopedics,

Trichy SRM Medical College

Hospital and Research Centre

(Affiliated to the Tamilnadu Dr.

MGR Medical University,

Chennai), Tiruchirapalli, Tamil

Nadu, India

Gulam Mohideen M

Department of Orthopedics,

Thanjavur Medical College

(Affiliated to the Tamilnadu Dr.

MGR Medical University,

Chennai), Thanjavur, Tamil

Nadu, India

Rathinasabapathy $\mathbf{R}$

Department of Orthopedics,

Thanjavur Medical College

(Affiliated to the Tamilnadu Dr.

MGR Medical University,

Chennai), Thanjavur, Tamil

Nadu, India
Corresponding Author:

Kanagasarathy K

Department of Orthopedics,

Trichy SRM Medical College

Hospital and Research Centre

(Affiliated to the Tamilnadu Dr.

MGR Medical University,

Chennai), Tiruchirapalli, Tamil

Nadu, India

\section{Study on management of infected nonunion of long bones by bifocal osteosynthesis of ilizarov's principle with the limb reconstruction system}

\author{
Kanagasarathy K, Gulam Mohideen M and Rathinasabapathy R
}

DOI: https://doi.org/10.22271/ortho.2019.v5.i4c.1662

Abstract

Infected nonunion is one of the most challenging limb threatening orthopaedic complications in sense of treatment and management where considerable morbidity are observed. Thus the patients are having social, financial, physical, and mental impacts Significant progress has been made in the management of infected nonunion in the last decade with appropriate pre-operative evaluation and treatment strategy. The main objective of this study to find out the effect of segmental transport in the management of infected, non-union of long bones by Ilizarov's concept using the Limb Reconstruction System (LRS). A total of 16 cases included in this study where 14 and 2 were males and females respectively. All the infected non-union of long bones cases was included in this study. Bone healing and functional results were evaluated. Most of the patients are in between the age groups of 31 and 50. While observing the site of the non-union cases, femer found maximum with 9 cases followed by tibia and humerus with 6 and one cases respectively. Reunion was successful in all cases thereby 10 cases classified as excellent; 3, 2 and 1 cases as fair, good and poor respectively. In this study, three major complications including shortening, knee stiffness and axial deviation were observed during post operative and follow-up periods. The method of treatment of infected non-union by the monolateral external fixator with a predictable healing of non-union and control of infection is well shown in this study. Careful preoperative planning, appropriate surgical techniques and adequate follow-up, will definitely make this method a very successful one.

Keywords: Non-union of long bones, osteosynthesis, LRS, management

\section{Introduction}

Nonunion of long bone fractures has become a common problem in orthopaedic practice. Non union of a fracture can occur both in conservative as well as in operative treatment ${ }^{[1,2,3]}$. When infection is added to non union, the condition becomes intractable. The treatment gets prolonged over many years and sometimes it ends in amputation. It is difficult to treat the non unions, more so in the case of infected non union because of the following reasons ${ }^{[4,5,6]}$.

- Non union had been operated more than 3 to 4 times resulting in cicatrisation of the soft tissue with an avascular environment around the fracture site.

- Sinus tract formation, leading on to the fracture site indicating dead bone or sequestrum inside.

- Considerable distance from the non union site of long bones, due to the thrombosis of blood vessels of Haversian cannals, resulting in necrosis of bone.

- Lingered immobilization, manifold surgical procedures with fibrosis of the muscles leads on to a stiff joint and may have fracture disease.

- Development of antibiotic resistance.

- Rate of limb length incongruity and malformations

- Erratic degree of soft tissue lost or defects requiring multiple sessions in reconstruction surgeries.

In the past, there were several authors, who put their mind in solving the problem by many methods, where in all the factors of non union like deformity, shortening, infection and abnormal movement were managed with questionable success. Some studies highlighted the usage of metallic intramedullary device to solve this problem with some success ${ }^{[7,8]}$. 
The other study concentrated on the viability of the fracture ends by massive onlay bone grafting that is also not very much useful $[9,10]$. The usage of plate osteosynthesis and an additional external fixator is also considered to increase the stability of non union site ${ }^{[11]}$. In all the above methodology, there is no way, by which vascularity of the non union site could be improved.

Later, the Russian Surgeon devised a method by which the basic factors of infected non-union like abnormal movements, gap, sinus and the poor vascularity of the ends were managed by a single procedure with predictable success ${ }^{[12]}$. The concept of bifocal osteosynthesis is distraction at osteotomy site and compression at non-union site ${ }^{[13]}$. Rhythmical distraction leads on the neo-osteogenesis and consolidation of corticotomy site. This procedure of transporting a segment of bone increases the vascularity of the fracture ends. Once the vascularity of the fracture ends increases, the infection will be eradicated and there will be healing of non-union ${ }^{[14,15,16,17]}$.

The occurrence of this nonunion in closed tibial fractures is observed as $2.5 \%$ and it increases five to seven fold for open fractures with gross contamination and extensive soft tissue damage. The bone defect is filled by bone transport, as described by Ilizarov corticotomy and distraction technique that forms new bone at the trailing end also known as distraction osteogenesis. The Ilizarov ring fixator offers multiplanar stability, facilitates in the modification of angulation, and rotation at the nonunion site much effectively $[15,16,17]$. Hence this study has the objective to find out the effect of segmental transport in the management of infected, non-union of long bones by Ilizarov's concept using the Limb Reconstruction System (LRS).

\section{Materials and Methods}

The study was conducted with 16 patients with infected nonunion of long bones, who were admitted in Thanjavur Medical College and Hospital, Thanjavur, India from July 2006 to March 2008. The inclusion criteria for the study include those with infected non-union of long bones. The noninfected non-unions, intra-articular fractures and fractures with neuro-vascular deficit were excluded. Diagnosis was established in all patients by the history and physical examination and the investigations. A history is taken from the patient including the date of injury, the detail of original accident and subsequent treatment.

On presentation, limb length measurements, range of motion of the joint, condition of skin and vascularity, co-existing ligamentous instabilities and general medical condition were evaluated. The condition of soft tissue surrounding the nonunion site is of paramount importance, because the presence of a cicatric, a draining sinus or a thin and un-yielding soft tissue envelope will certainly limit or redirect the surgical methods to be used. Preoperative radiographs of the affected extremity were taken. Anteroposterior and lateral $\mathrm{X}$ rays were taken and were evaluation.

Bone healing and functional results were evaluated according to a modified classification of the Association for the study and application of the method of Ilizarov (ASAMI) as described in table 1 .

Table 1: Evaluation of Bone healing and functional results

\begin{tabular}{|c|c|c|c|c|}
\hline Criteria & Excellent & Good & Fair & Poor \\
\hline $\begin{array}{c}\text { Bone } \\
\text { healing }\end{array}$ & $\begin{array}{c}\text { union without infection, with less } \\
\text { than } 7^{\circ} \text { deformity and less than } 2.5 \\
\text { cm leg-length inequality }\end{array}$ & $\begin{array}{c}\text { union with two out of } \\
\text { three criteria for an } \\
\text { excellent result present }\end{array}$ & $\begin{array}{c}\text { union with one of the } \\
\text { three criteria present }\end{array}$ & $\begin{array}{c}\text { non-union or refracture, } \\
\text { without any of the three } \\
\text { criteria fulfilled. }\end{array}$ \\
\hline $\begin{array}{c}\text { Functional } \\
\text { results }\end{array}$ & $\begin{array}{c}\text { if the patient was active, able to } \\
\text { accomplish his/her daily activities, } \\
\text { and the other four criteria were absent }\end{array}$ & $\begin{array}{c}\text { if the patient was active, } \\
\text { but one or two of the other } \\
\text { criteria were present }\end{array}$ & $\begin{array}{c}\text { if the patient was active, } \\
\text { with three or four of the } \\
\text { other criteria present }\end{array}$ & $\begin{array}{c}\text { if the patient was inactive, } \\
\text { regardless of the presence } \\
\text { of other criteria }\end{array}$ \\
\hline
\end{tabular}

The functional assessment was based on five criteria including observable limp; stiffness of knee or hip (loss of $>70 *$ of knee flexion, or loss of $>15^{*}$ of extension; loss of $>50 \%$ hip motion in comparison with the normal contralateral side; soft tissue sympathetic dystrophy; pain, that reduced activity or disturbed sleep; and inactivity (Because of unemployment or an inability to return to daily activities due to the injury).

The surgery of the upper and lower limbs was performed under general and spinal anaesthesia respectively. Initially, a thorough wound debridement was done along with removal of sequestrum and infected, necrotic materials followed by application of LRS. Intravenous antibiotics were given postoperatively and open corticotomy was performed as secondary proceudre. Among the other cases, where there was florid/active infection, corticotomy was deferred, until infection settled.
The first screw to be inserted is the most proximal one, which will engage the thick calcar bone at a point just above the lesser trochanter, avoiding the capsule of the hip joint. The appropriate screw guide is now selected and inserted using the trocar to locate midpoint of bone. It is then locked into 4th seat of proximal clamp of bone. The correct length $4.8 \mathrm{~mm}$ drillguide is now inserted into screw guide and using $4.8 \mathrm{~mm}$ drill bit, first and second cortices are drilled. Both are then removed and Schanz screw is inserted using T-handle (Figure 1). The next screw to be inserted is the most distal one. The position of distal screw is critical, since, if it is incorrectly placed, the screws in the middle clamp may miss the bone (Figure 2). The screw seats 1, 2 and 4 (Starting from proposed osteotomy site) in proximal clamp are used. Among the middle and distal clamps, screw seats 1 and 5 are used (Figure 3). 


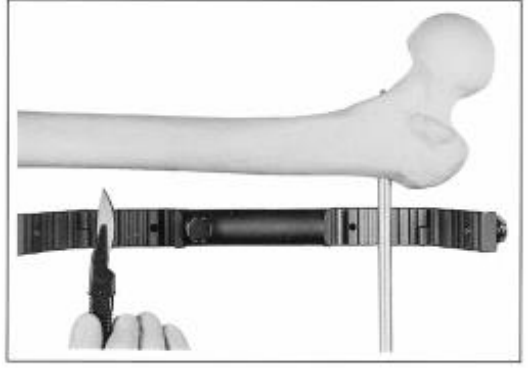

Fig 1: Insertion of $1^{\text {st }}$ screw

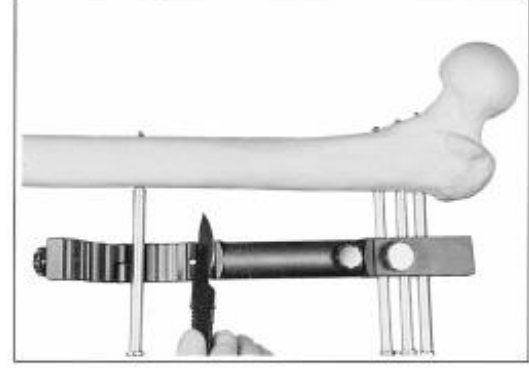

Fig 2: Insertion of next screws

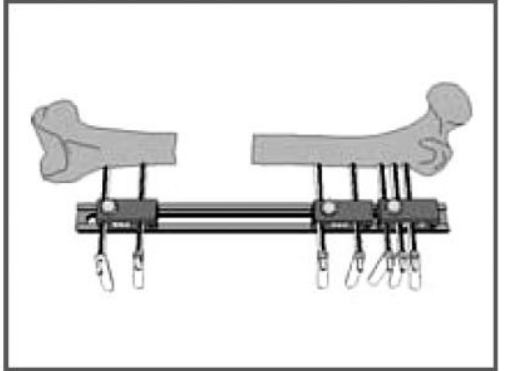

Fig 1: Insertion of screw seats
The remaining screws are inserted in a similar fashion and the clamp templates are locked to the rail. The Limb reconstruction system is now applied. The clamp templates are now removed and straight clamps are applied at distance of $2 \mathrm{~cm}$ between the skin and the rail (Figure 4). Osteotomy was done and the transport fragment is then advanced $1 \mathrm{~mm}$ to ascertain that the osteotomy is complete. Then the wound is closed without any distraction. A screw guide with drill guide is now placed on the bone and a series of controlled drill holes made across the bone, penetrating the farcortex each time. A drill stop is used to prevent damage to the soft tissues (Figure 5). The holes are connected with an osteotome and since the bone has been pre-tensioned the bone ends will gently drift apart once the osteotomy has been completed (Figure 6).

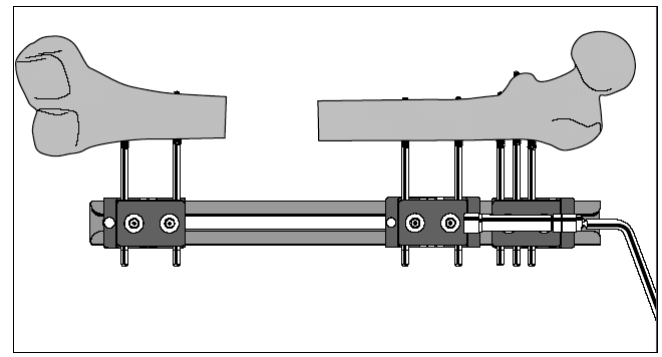

Fig 4: Application of LRS

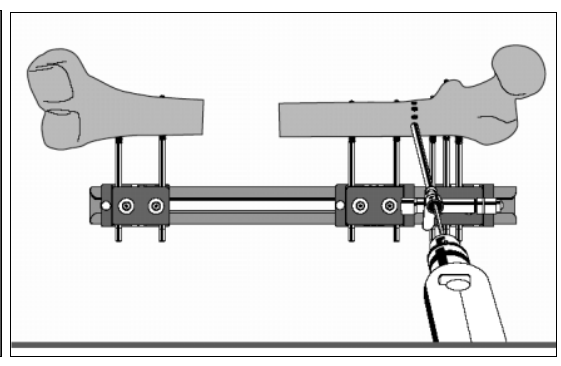

Fig 5: Usage of drill stop

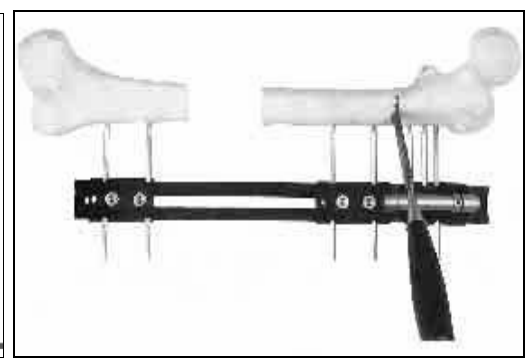

Fig 6: Osteotome connect
Completeness of the osteotomy is confirmed by exploration of the gap using a probe, assessment of the ease of distraction and the appearance under image intensification (Figure 7). The osteotomy is then gently compressed, the periosteum reconstituted in cases, where it has been incised, and the wound closed with a drain (Figure 8). The knee is now flexed and extended to ensure that the skin around the screws is not under tension and to allow for easy movement of muscles and fascia. An X-ray is taken to check that the lengthener has been mounted parallel to the diaphysis.

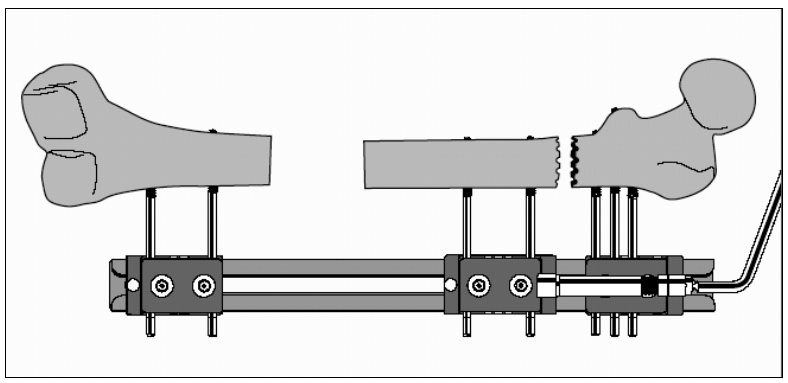

Fig 7: Image intensification

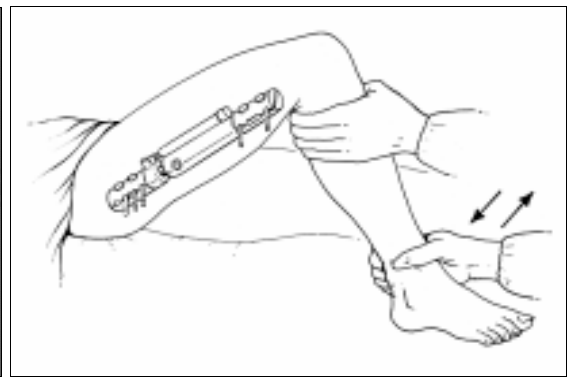

Fig 8: Compression of Osteotomy
Distraction was started and done after a lag period of 7 to 10 days rhythmically at a rate of $0.25 \mathrm{~mm}$ every six hours. The patient was given training in rhythmic distraction, and advised it was important to follow the same till the distraction is over. The rate of distraction should be temporarily increased, where rapid ossification is observed or reduced, if ossification is slow or if the patient complains of pain or muscle contraction. The actual time points at which progressive loading and weight bearing will occur will depend upon whether the fracture is stable or unstable. As a general rule, however, it can be stated that in stable fractures, progressive loading should commence 2-4 weeks postoperatively, and in unstable fractures, 5-8 weeks post-operatively. The patient should commence weight bearing with crutches the day after the operation. The waiting period before starting distraction is normally ten days in adults and about five days in children and patients with rapid ossification

After $1 \mathrm{~cm}$ of lengthening has been achieved, an X-ray is performed to ensure that distraction is taking place correctly. The patient is then allowed to leave hospital and advised to take X-ray every 30-40 days to check that osteogenesis. If the density of the lengthened portion is poor, but uniform, lengthening is stopped for one or two weeks. If the callus is irregular, the segment is compressed by one or two centimetres at the same rate as for lengthening, until the callus is uniform, when lengthening is resumed.

At the end of lengthening, the X-ray should show a uniform callus. The lengthener body is now locked to maintain the 
new bone in stable neutralization. The compressiondistraction unit is no longer required and is removed at this stage to make the assembly lighter. When the X-ray shows that the segment is uniformly dense and opaque, dynamization is commenced by loosening the central body locking nut. During dynamization, weight bearing on the lengthened limb should be total.

Pins were removed, once we see periosteal tube at the distraction site and atleast 3 cortices in AP and lateral views. The lengthener is removed, once X-rays and clinical assessment indicate good bony consolidation. Radiological and clinical review should be carried out 6 months after fixator removal. First, the central body locking nut is tightened to maintain the exact length of the fixator prior to removal, in case the fracture should require a further period of fixation. The fracture can be manipulated after removal of the fixator to ensure that clinical healing has been achieved.

If there is any doubt regarding clinical and radiological healing and provided the screws are well-tolerated, the fixator can remain in situ for a further period of two weeks. If the clinical and radiological healing has been achieved, the fixator and screws can be removed immediately as a simple outpatient procedure. The screw entry holes are then usually dressed every two days, until they close spontaneously, which normally takes place after 7-10 days.

\section{Results}

Union was achieved in all 16 cases, but delay in union was observed in two cases $(12.5 \%)$. The average time for union was 3 months. Among the subjects included in this study, male and female patients were 14 and 2 respectively and the age group varies from 8 years to 46 years (Figure 9).

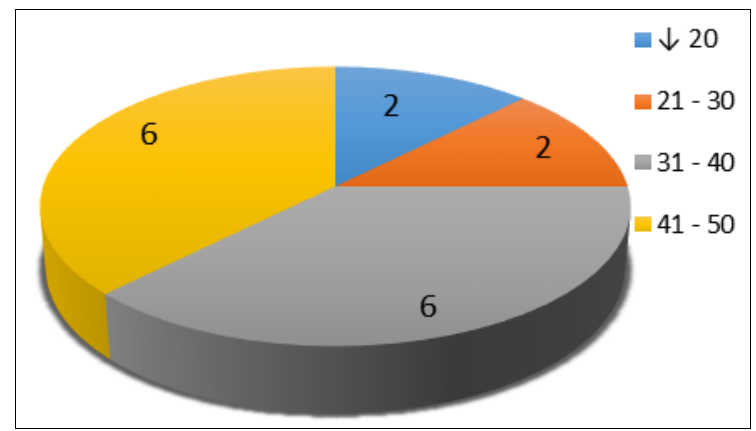

Fig 9: Age wise distribution of the subjects

The site of non-union and number of cases with duration of non-union varies from 6 to 15 months were depicted in table 2. The various clinical observations among the subjects during admission was depicted in table 3. The side of fractures are observed as $10(62.5 \%)$ and $6(37.5 \%)$ among right and left limb respectively. Among the types of nonunion, atrophic and heterotrophic were found among 14

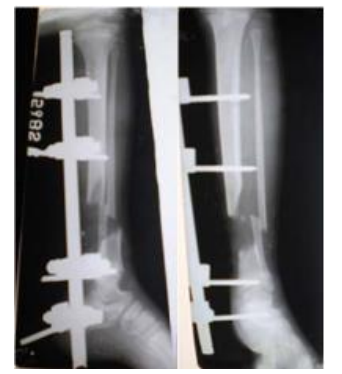

a. Preoperative with external fixator
$(87.5 \%)$ and $2(12.5 \%)$ cases respectively. According to the ASAMI criteria, the reunion of the fractures were successful in all cases thereby the classification criteria was depicted in figure 10 .

Table 2: Site and duration of non-union

\begin{tabular}{|c|c|c|}
\hline $\begin{array}{c}\text { Site of the Non- } \\
\text { union }\end{array}$ & $\begin{array}{c}\text { Number of cases } \\
(\mathbf{n}=\mathbf{1 6})\end{array}$ & $\begin{array}{c}\text { Average duration of } \\
\text { non-union }\end{array}$ \\
\hline Femur & $9(56.2)$ & 8 months \\
\hline Tibia & $6(37.5)$ & 7 months \\
\hline Humerus & $1(6.3)$ & 15 months \\
\hline
\end{tabular}

(Figure in parenthesis denoted percentages)

Table 3: Various clinical observations

\begin{tabular}{|c|c|}
\hline Observations & No. of subjects $(\mathbf{n = 1 6})$ \\
\hline Open fractures & $12(75)$ \\
\hline Infected implants & $4(25)$ \\
\hline Sinus discharge & $15(93.7)$ \\
\hline Stiff non-union & $2(12.5)$ \\
\hline Mobile non-union & $14(87.5)$ \\
\hline
\end{tabular}

(Figure in parenthesis denoted percentages)

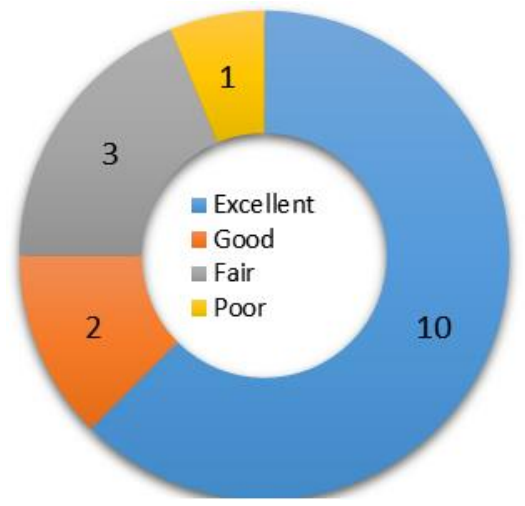

Fig 10: Observation of ASAMI classification

Further, it was noted that the gap at non union site varies from $1.2 \mathrm{~cm}$ to $6 \mathrm{~cm}$. Our follow up varies from 4 months to 12 months, with an average of 8 months. The nonunion site united in all the cases by the end of $12^{\text {th }}$ week. The sinus got cleared in all the 16 cases by the end of $5^{\text {th }}$ week. There was no difficulty in this series as far as the transportation phase in concerned.

There was a considerably delay in the consolidation phase in all cases. Of them, 2 cases had pin tract infection. Hence the fixator was removed and functional cast brace was applied. After a period of waiting for the consolidation to occur, the final result of the healing of the osteotomy with good bone healing in about 8 cases, a delay in healing in 6 cases, 2 cases had delayed union, which needed bone grafting. In all the cases, there was no infection in the osteotomy site. The pre and post operative observations with external fixator and LRS were impregnated in figure 11.

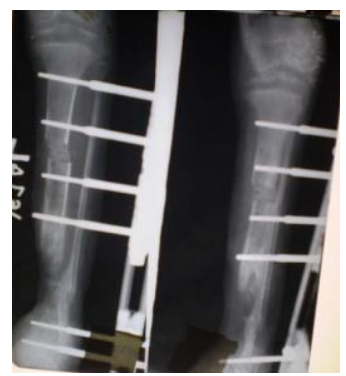

b. Postoperative with LRS

Fig 11: Pre (a) and post (b)-operative observations of external fixator (a) and LRS (b) 
Refracture occurred in one case, which was treated by removal of the fixator and reapplication of fixator. Premature consolidation of corticotomy site occurred in one case, which was treated by recorticotomy and bone transport. Axial Deviation occurred in one case on fixator removal, when the callus is still plastic and is due to increased muscular tension or weight bearing and early removal of fixator. The corticotomy and knee mobilization with follow ups were depicted in figure 12 .

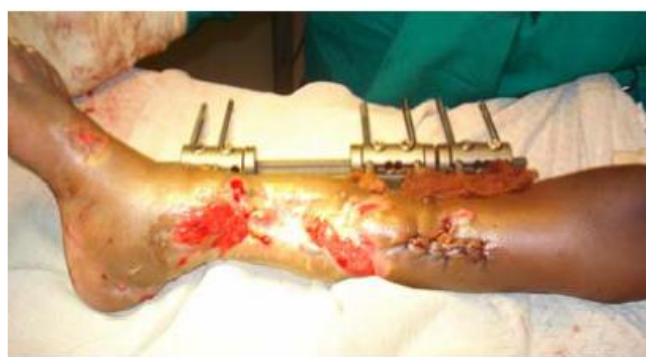

a. Corticotomy and Distraction

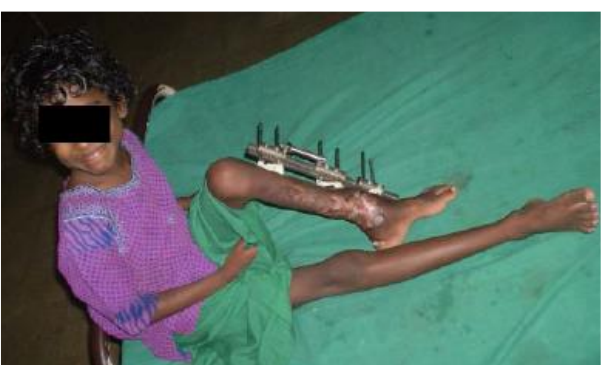

b. Knee mobilization

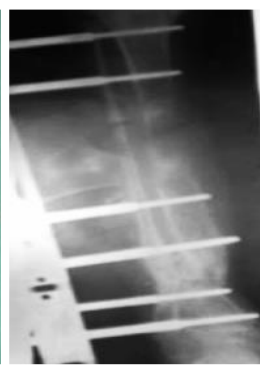

c. Follow-up

Fig 12: Observation of corticotomy and knee mobilization with follow ups

One patient was HIV positive, who had supracondylar femur fracture and fixator was applied spanning knee. But, due to florid, uncontrolled infection, the patient went in for above knee amputation. Of the nine cases of Femoral non-union, there were three cases of knee joint stiffness, but corrected to some extent later. Of the six cases of Tibial non-union, two

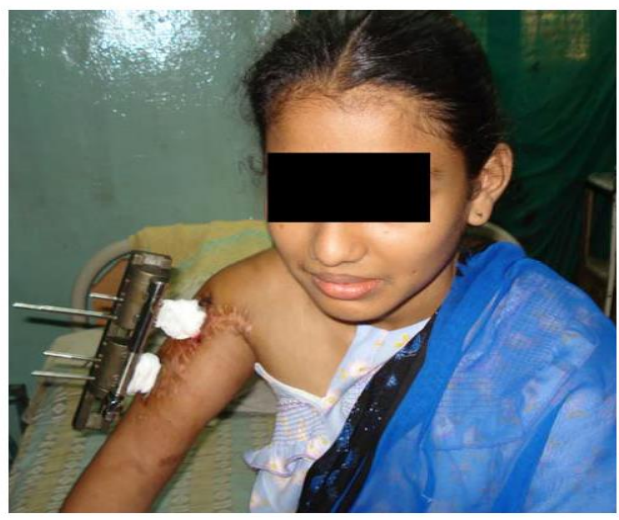

a. Post-operative cases had shortening of leg with an average of about $1.5 \mathrm{~cm}$. Of one case of Humerus nonunion, there was a shortening of $1.75 \mathrm{~cm}$. The observations of performance of acute docking in patients in pre-operative state and follow-up were depicted in figure 13 .

Fig 13: Observations of acute docking in patients in pre-operative state and follow-up

In this study, three major complications were observed and recorded among the patients in post operative and follow-up

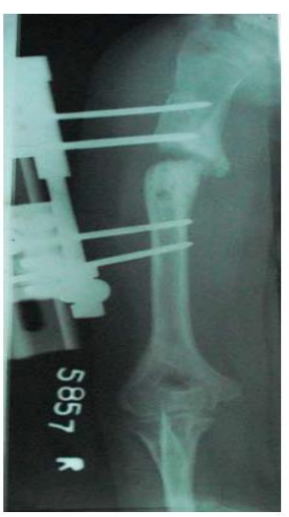

b. Acute docking

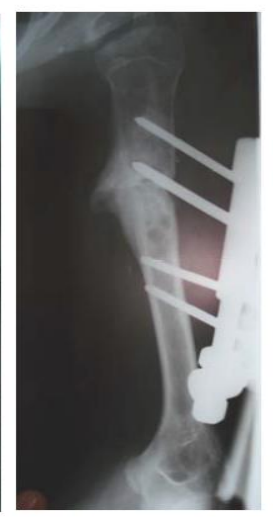

c. Follow-up

periods including shortening (figure 14a), knee stiffness (figure 14b) and axial deviation (figure 14c).

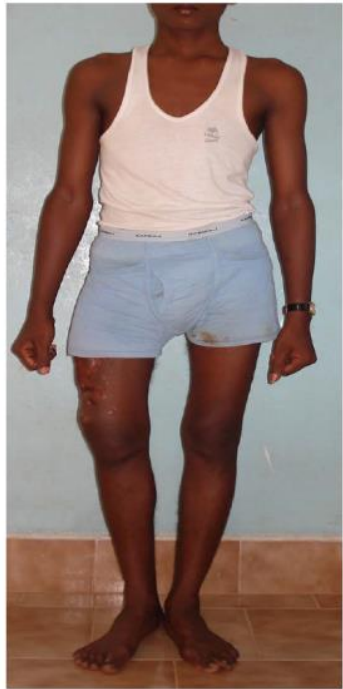

a. Shortening

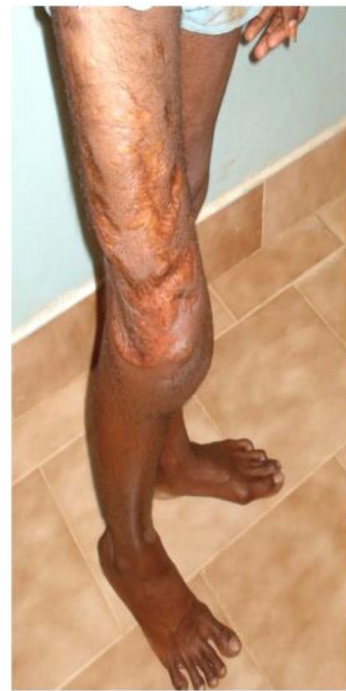

b. Knee stiffness

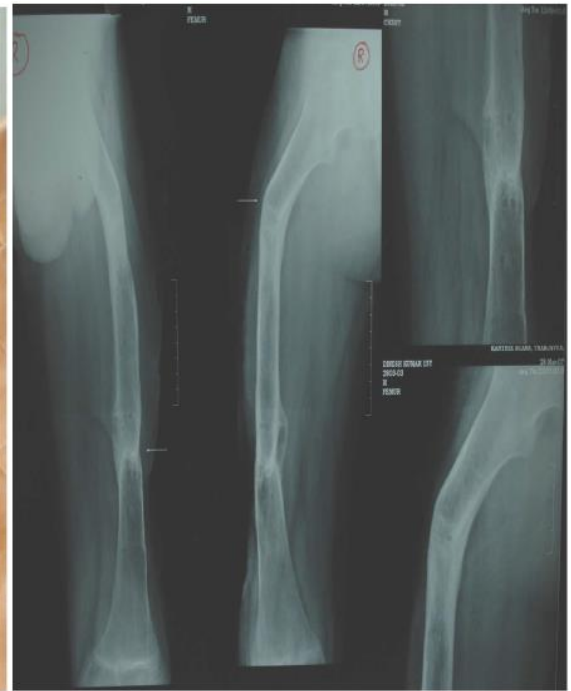

c. Axial deviation

Fig 14: Observation of major complications 


\section{Discussion}

The tremendous interest has been observed in distraction osteosynthesis. The clinical fact is distraction can produce new bone formation. The effect of rhythmical distraction which generates new bone formation was enlightened by Ilizarov $[18,19,20]$. The effect of corticotomy on increased vascularity of the whole limb as well as the fixator in the fracture site was still under study ${ }^{[13]}$.

The distraction on tensile force at the corticotomy site, the lining cells covering the bone ends are able to differentiate into osteogenic and chondrogenic cells under an adequate stimulus and environment and are called as osteosynthesis or intramembranous ossification ${ }^{[21]}$. This type of regeneration of bone can be obtained by an appropriate distraction rate. This rate appears to be critical in the new bone formation and maintenance of adequate blood supply ${ }^{[22,23]}$.

In the present study, monoplanar external fixator was used and appropriate rhythmical distraction was done. About $80 \%$ of cases showed good periosteal tube of new bone formation. Due to the preservation of medullary blood supply, the corticotomy is better than osteotomy ${ }^{[24]}$. It is difficult to achieve a true corticotomy, however, and since there is now considerable evidence of the rapid recovery of the medullary blood supply following a complete osteotomy, the latter is normally performed today ${ }^{[25]}$.

It is important, however, to preserve the periosteum, since this layer has been demonstrated to be a most important site of osteogenesis. The site chosen for the osteotomy should ideally, be metaphyseal or immediately submetaphyseal, since this is a wider and more vascular region and has been shown to have better osteogenic potential than the diaphysis. The effect of corticotomy on the healing of bone was also explained by intact intramedullary blood supply by microangiographic studies ${ }^{[24,26]}$.

It is experimentally proved that there is no difference in regeneration to the healing sequence, in rhythmical distraction either after corticotomy or after osteotomy. The microangiographic study is essential at this juncture to prove that there is intact medullary tube after corticotomy in this series ${ }^{[24,26]}$. The corticotomy in the metaphyseal region has been done in the most of cases in the diaphyseal region, which may called in other words as callostasis or callus distraction [27].

Callostasis was usually done after a lag period of 2 weeks in adults and 10 days in children $[24,28]$. In the present study, there was a considerable delay in the consolidation phase of many cases, which may be shortened in time by bone grafting and plating at the osteotomy site where other studies also done by using similar AO/ASIF tubular fixation in the segmental defect ${ }^{[29]}$. The present series showed a good response in eradicating the intractable infection within 5 weeks and union at non union site in $95 \%$ of cases, the healing the lesions has viewed critically for a period of 2-4 years before declaring the lesion is healed.

Union achieved by repairing defects with cancellous grafts may prove to be acceptable alternatives [24, 30]. The biomechanical structure of the restored bone may require years to remodel to achieve the radiological appearance of that obtained by distraction regeneration ${ }^{[31]}$. Recent advances in microvascular anastomosis technology have permitted vascularised osseous transfers for dealing with missing bone tissue. In the lower limb, grafts, whether fibula or iliac crest take years to hypertrophy and often fracture one or more times before complete remodelling ${ }^{[32]}$.

Some studies showed that only $40 \%$ of patients with osseous sepsis went on to unite microvascular osseous transplants [24, 33]. Indeed, it is a good method for the management of intractable infective non union of long bones with success rate of $95 \%$ as far as the eradication of infection and union at nonunion site is concerned ${ }^{[3,34,35]}$. In this study all the cases are treated appropriately and overall, the outcome following treatment of infected nonunion are good to excellent.

\section{Conclusion}

The method of treatment of infected non-union by the monolateral external fixator with a predictable healing of nonunion and control of infection is well shown in this study. Though there are some complications with this method, it can be overcome by careful preoperative planning, appropriate surgical techniques and adequate follow-up, which will definitely make this method a very successful one.

\section{References}

1. Leiblein M, Verboket R, Marzi I, Wagner N, Nau C. Nonunions of the humerus - Treatment concepts and results of the last five years. Chinese Journal of Traumatology. 2019; 22:187-95.

2. Mills L, Tsang J, Hopper G, Keenan G, Simpson AH. The multifactorial etiology of fracture nonunion and the importance of searching for latent infection. Bone Joint Research. 2016; 5:512-9.

3. Motsitsi NS. Management of infected nonunion of long bones: the last decade (1996-2006). Injury. 2008; 39:15560.

4. Jain AK, Sinha S. Infected nonunion of the long bones. Clinical Orthopedics and Related Research. 2005; 431:57-65.

5. Kundu ZS, Gupta V, Sangwan SS, Kamboj P. Gap nonunion of tibia treated by Huntington's procedure. Indian Journal of Orthopedics. 2012; 46:653-8.

6. Satya RP, Dasarath K, Divya M, Naresh KP, Saswat S, Meini $\mathrm{M}$ et al. Management of infected non-unions of long bones using limb construction system (LRS) fixator. International Journal of Research in Orthopedics. 2017; 3:213-9.

7. Prochaska VJ, Lindgren JU. Treatment of chronic tibial osteomyelitis, segmental bone loss, soft tissue damage by bone transport. Nebraska Medical Journal. 1994; 79:34952.

8. Fernandez FF, Langerndorfer M, Wirth T, Eberhardt O. Failures and complications in intramedullary nailing of children's forearm fractures. Journal of Child Orthopedics. 2010; 4:159-67.

9. Paley D, Catagni MA, Argnani F, Villa A, Benedetti GB, Cattaneo R. Ilizarov treatment of tibial non-unions with bone loss. Clinical Orthopedics. 1989; 241:146-65.

10. Wang W, Yeung KWK. Bone grafts and biomaterials substitutes for bone defect repair; a review. Bioactive Materials. 2017; 2:224-47.

11. Sonderegger J, Grob KR, Kuster MS. Dynamic plate osteosynthesis for fracture stabilization: how to do it. Orthopedics Reviews (Pavia). 2010; 2:e4.

12. Bassiony AA, Almoatasem AM, Abdelhady AM, Assal MK, Fayad TA. Infected non-union of the humerus after failure of surgical treatment: management using the Orthofix external fixator. Annals of Academy of Medicine Singapore. 2009; 38:1090-4.

13. Ramji LS, Rajni R. Treatment of complex nonunion of the shaft of the tibia using lizarov technique and its functional outcome. Nigeria Medical Journal. 2016; 
57:129-33.

14. Lee DK, Duong ET, Chang DG. The Ilizarov method of external fixation: Current intraoperative concepts. Association of Operating Room Nurses Journal. 2010; 91:326-37.

15. Phieffer LS, Goulet JA. Delayed unions of the tibia. Journal of Bone and Joint Surgery America. 2006; 88:206-16.

16. Kawoosa AA, Majid S, Mir MR, Mir GR. Results of tibial lengthening by Ilizarov technique. Indian Journal of Orthopedics. 2003; 37:7-12.

17. Wani N, Baba A, Kangoo K, Mir M. Role of early Ilizarov ring fixator in the definitive management of type II, IIIA and IIIB open tibial shaft fractures. International Journal of Orthopedics. 2011; 35:915-23.

18. Ilizarov GA. Clinical application of the tension-stress effect for limb lengthening. Clinical Orthopedics. 1990; 250:8-26

19. Ilizarov GA, Ledyasev VI, Shitin VP. Experimental studies of bone lengthening. Eksp Khir Anesteziology. $1969 ; 14: 3-12$.

20. Spiegelberg B, Parratt T, Dheerendra SK, Khan WS, Jennings R, Marsh DR. Ilizarov principles of deformity correction. Annals of Royal College of Surgeons England. 2010; 92:101-5.

21. Suganthi DD, Sreekumar K. A study on application of Ilizarov ring fixator in tibial lengthening. International Journal of Orthopedic Sciences. 2019; 5:398-400.

22. Ryan ET, Matthew JS. Skeletal blood flow in bone repair and maintenance. Bone Research. 2013; 1:311-22.

23. Marenzana M, Arnett TR. The key role of the blood supply to bone. Bone Research. 2013; 3:203-15.

24. Dabis J, Templeton-Ward O, Lacey AE, Narayan B, Trompeter A. The history, evolution and basic science of osteotomy techniques. Strategies Trauma and Limb Reconstructions. 2017; 12:169-80.

25. Hasler CC, Krieg AH. Current concepts of leg lengthening. Journal of Child Orthopedics. 2012; 6:89104.

26. Peek AC, Timms A, Chin KF, Calder P, Goodier D. Patterns of healing: a comparison of two proximal tibial osteotomy techniques. Strategies Trauma and Limb Reconstructions. 2016; 11:59-62.

27. Furmetz J, Soo C, Behrendt W, Thaller PH, Siekmann H, Bohme $\mathrm{J}$ et al. Bone transport for limb reconstruction following severe tibial fractures. Orthopedic Reviews (Pavia). 2016; 8:6384-9.

28. Natu SS, Ali I, Alam S, Giri KY, Agarwal A, Kulkarni VA. The biology of distraction osteogenesis for correction of mandibular and craniomaxillofacial defects: A review. Dental Research Journal (Isfahan). 2014; 11:16-26.

29. Zhang Q, Zhang W, Zhang Z, Zhang L, Chen H, Hao M et al. Femoral nonunion with segmental bone defect treated by distraction osteogenesis with monolateral external fixation. Journal of Orthopedic Surgery Research. 2017; 12:183-9.

30. Tak MW, Tak WL, Xin L, Christian F, Kelvin Y, Frankie L. Masquelet technique for treatment of post-traumatic bone defects. The Scientific World Journal. 2014: Article ID 710302.

31. Amini AR, Laurencin CT, Nukavarapu SP. Bone tissue engineering: recent advances and challenges. Critical Review in Biomedical Engineering. 2012; 40:363-408.

32. Singh A, Ghosh S, Chaudhuri A, Datta S, Chowdhury A,
Roy DS. Ilizarov fixator in management of nonunited and infected tibial shaft fractures. Medical Journal of DY Patil University. 2015; 8:35-40.

33. Sun Y, Zhang C, Jin D, Sheng J, Cheng X, Liu X et al. Free vascularised fibular grafting in the treatment of large skeletal defects due to osteomyelitis. International Journal of Orthopedics. 2010; 34:425-30.

34. Devnani AS. Simple approach to the management of aseptic non-union of the shaft of long bones. Singapore Medical Journal. 2001; 42:20-5.

35. Struijs PA, Poolman RW, Bhandari M. Infected nonunion of the long bones. Journal of Orthopedics and Trauma. 2007; 21:507-11. 